\title{
Study on the Position and Application of Mathematics in the Teaching of Economics
}

\author{
Liu Hao \\ Dalian Jiaotong University, Liaoning, Dalian116045 \\ 348261562@163.com
}

Keywords: Mathematics; Economics; Economics teaching; Logic

\begin{abstract}
The application of mathematics in economics has already become an indisputable fact. However, the abuse of mathematics in economics is also a controversial question. In this paper, we analyze the difference and connection between mathematics and economics, and point out that the economics research should also be based on the economic reality and economic theory. Mathematics is only a kind of tool or means which can describe the theory. And we can't use other things to substitute for it. And based on it, we discuss how to deal with the mathematics content involved in different teaching contents in economics teaching.

In recent years the development of economics and mathematical relationship has already presented the distorted phenomenon. The economics has presented an tendency of excessive mathematization. On the one hand, more and more difficult mathematical formulas, symbols and derivations have appeared in the theoretical study. On the other hand, "in the economics classroom we can finish teaching a lesson only by making the blackboard be covered with figures and charts without the observation and discovery of anything happened in the real world" (1). Therefore, if we want to jump out of this kind of "vicious cycle" and improve the quality and effect of economics teaching, we must clear the role and status of mathematics in economics teaching.
\end{abstract}

\section{The Learning of the Disciplinary Differences between Economics and Mathematics}

When we think about the human behavior with economics, we tend to relay on a kind of introspective thinking process more. Starting from their inner feelings, we are based on the understanding of logical sense and speculate the object which we want to study. While according to the general definition we think that mathematics is a science which studies the space form and quantity relationship in the real world. It is produced by the objective world, but it is higher than the objective world by the abstraction and reasoning. The mathematics and economics both take the study of the objective world as their own duties. Even some research ways are also similar. Then what factors construct the disciplinary boundary between them?

First of all, seen from the formation mechanism, if the economics research wants to get a certain conclusion, generally it needs three stages, such as the presentation of economic concepts or guess, model validation, economic policy suggestions. Among them the presentation of economic ideas comes from the economic intuition, the historical experience and the external experience. The presentation of economic policies also needs to use the plain language to express so as to let the ordinary people to understand. So the only stage which needs to use the mathematical tools is the modeling stage in the middle. It is obvious that in the process of economic research, the mathematics is not everything but it is merely used to a step to verify the economic ideas. 
Secondly, seen from the logical bases, the economics has three logical bases, such as the historical logic, the realistic logic and the mathematical logic. Among them, the historical logic requires that the economic theory must be in conformity with the historical trail of economic phenomenon. The realistic logic requires that the logic process must be in conformity with the process of economic things in the real economic activity. And it emphasizes the widespread contact of economic events. While the mathematical logic mainly refers to the various mathematical methods used in the economics.

\section{The Clarification of the Relative Relation between the Research and Mathematics}

Since economics research is the secular people's behavior. Besides, there are also essential differences between economics research and mathematics. Then why it shows that the postgraduate students in the world famous universities lack the interest of the real economy and the economics literature unexpectedly in a survey and on the contrary, we acutely realize that the successful men in the economic field are basically those people who have the knowledge of mathematical economics and econometrics? Why the dominant position of the taught economics in the institutes is increasingly being substituted by the formal technical analysis expect for the understanding of the history and the system? Therefore, it is necessary for us to clear what kind of relationship economic theory and mathematics exactly in the study and research of economics.

We want to see from the birth of economics to its different development stages, mathematics plays an indelible role. We can see the following specific effects from the mathematics. (1) Mathematics makes the expression of economics be more precise and concise. Especially for the mathematical language on the set of assumptions, many controversies caused by the unclear definition can be reduced. For example, the classic rational man hypothesis clearly excludes the "altruistic motives" which may exist in the people's economic behavior. (2) The rigorous logic of mathematical analysis can avoid the abuse of the theory by explaining the boundary and adaptive range of establishing an economic conclusion. For example, when it comes to property issues in microeconomics, usually people only think that "the transaction cost is zero" is the only premise for the establishment of Coase Theore. However, many people ignore that the utility (payment) function is this condition, quasi linear ( Mr Coase himself also ignored this hypothesis when provided his argument). (3) The development of mathematical techniques can improve the existing economic theories. For example, the emergence of game theory spreads the isolated individual behavioral decision research in economics to the discussion of the interpersonal interactive behavior. (4) Using the mathematics can get some less intuitive results. For example, the theory of the invisible hand holds the opinion that as long as the supply and demand are not equal, the competitive market will use the invisible hand to achieve the market equilibrium through the adjustment of the market price. But this conclusion in the reality is not always true. Scarf (1960) shows us the specific example based on the operation rules for the numerical solution of certain equilibrium model.

However, we also see that if a theory wants to become a scientific theory, on the one hand, on the internal logic it should be self-consistent. That is to say, by a certain mechanism it can explain that several variables in the theory model have a causal relationship. At the same time it ensures that the theoretical reasoning and the empirical phenomenon connect with the outside factors and both of them must be consistent. Therefore, if the economic research only relies on the derivation of mathematical formula, although it can ensure the consistency of the internal logic it often divorces from the reality to make the research be lack of practical significance. Because the use of mathematics not only can explain the truth but also it is likely to cover a mistake. If the 
mathematical method can be used properly, it can solve some problems of economics which using the language and words cannot solve. The improper application can make the conclusion of the research get mistakes. For example, Western scholars think that generally once the equilibrium theory comes to Aluo Debulu, it won't offer the requirements of any description on the reality economic system any longer. While it changes into a pile of pure normative tools. At the same time it also becomes a perfect example of the so-called "blackboard economics".

\section{The Grasp of Mathematical Tool Scale in the Economics Teaching}

First, economics is the teaching of introductory stage. The economics teaching of this stage is mainly based on the building of the students' economic intuition and the learning of some basic economics concepts and some basic theories. Due to the incomplete system of market economy in our country, some habitual economics phenomena and the knowledge commonly used by the students many western countries are not intuitive for the students in our country. The students can only understand them by insight and force themselves to recognize them through the teachers' oral expression. Therefore, in this stage if we use a large number of mathematical tools without careful consideration it will make the students can't find proper approach and enter in the learning process so as to lack the understanding of economics thought to fall into the myth of the mathematical deduction. But this kind of worry doesn't mean that at this stage the teaching needs the "demathematics". Because this stage it still needs to use a lot of "typical facts" to strengthen students' cognition of some economics concepts and theories. However, these "typical facts" contain all kinds of data, charts and simple statistical analysis. For example, if we use the words to express the demand law which the students contact with first, it can be expressed that the demand of the consumers falls if the price rises, and on the contrary the demand of the consumers rises if the price falls. But if we use mathematical language to express, a curve with the downward sloping to the right on the coordinate axis can show this law clearly. The students will be clear at a glance. At this time the simplicity of mathematical language will be exposed clearly.

Second, with the deepening of the economics study, the knowledge of economics taught in the class will be theorized increasingly, or we will be access to more and more basic problems. In other words, if the introduction stage of economics just lets the students know "what they are", then afterwards the intermediate and advanced study of economics will let the students know "why they would be like". Because, most of the contents of this part need the mathematics to be able to explain more clearly, such as the existence proof of general equilibrium from Aluo Debulu, the existence proof of nash equilibrium from Nash and others, the derivation of Oman on the solution of Von Neumann and Morgan Stein in cooperative game without the additional payment, etc. Although these research results benefit the development of mathematics, and themselves are not directly involved in the specific economic problems, it has great significance to analyze and solve economic problems. Therefore, we cannot simply delimit them into the list of "the abuse of mathematics" because of "no specific problem" and "lengthy and tedious formula". Then we must spend more energy to analyze the mathematical logic of these basic problems for the students in the teaching.

\section{Conclusion}

By the above analysis we can think that in the teaching and learning of economics, the blindly abandon or blindly appreciation of mathematics are both the behaviors with the hypercorrection. In the big background of contemporary economics research, it is an undisputed fact that the mathematics can be considered as a ticket to join in the economists club. However, if we consider 
the means as the purpose due to the things mentioned above, and we are willing to be the slave of mathematics in the economics research, it is also very unwise. After all, the task of economics is still to explain economic phenomena, predict the economic phenomena so as to have a better understanding of the society and promote the progress of the society. This is the reason why in 1980s when the mathematical economics reaches its peak the articles published in 1990s by ten most bright young economists who can use the mathematical model best can only use very simple mathematics. As an economics teacher, I should encourage the students to learn the mathematical tools and at the same time learn to take the rational man as the starting point to observe the phenomenon and seize the main variables directly behind the t phenomenon to build a new ability of theoretical model. Especially, only we grasp this kind of ability can we face the challenge of China's economists put forward by China's reform and development and the opportunity which this kind of challenge brings to China's economists.

\section{References}

[1] Hu Weiqing. The Mathematical Scale Used by Economics. Statistical Research, 2006(1).

[2] Zhang Zhen. The Analysis of Mathematical Problems with the Application of Economics, Mathematics and Economics [J]. Studies in Dialectics of Nature, 2005(10).

[3] Zhao Lei, Zhao Xiaolei. The Non-mainstream Interpretation of Economics Formalization. Journal of Sichuan Normal University (Social Science Edition), 2012(1).

[4] Ding Xiaoqin, Wang Chaoke. The Mathematical Conditions for the Usage of Economics. Economic Survey, 2008(2). 